\title{
A importância da mensuração e da análise de ROI no capital humano e sua influência nas decisões de investimento
}

\author{
The importance of measuring and analyzing ROI on human \\ capital and its influence on investment decisions
}

\section{La importancia de medir y analizar el ROI del capital humano y su influencia en las decisiones de inversión}

\author{
Carmen Cristina \\ Fernandes Andalaft ${ }^{1}$
}

\begin{abstract}
${ }^{1}$ Psicóloga especialista em Psicologia Organizacional e do Trabalho, especialista em Coaching Cognitivo, MBA em Recursos Humanos pela Universidade Santa Cecília, formação internacional em Coaching, Mentoring e Holomentoring ISOR - Professional Self \& Life e Ativação de Competências Pessoais pelo Instituto Holos. Orcid: https://orcid. org/0000-0003-0119-7477. E-mail: carmenandalaft@gmail.com
\end{abstract}

Recebido para publicação em: 8.4.2021

Aprovado em: 26.4.2021

\section{Resumo}

Há muito as áreas de recursos humanos $(\mathrm{RH})$ buscam ser reconhecidas pelo valor que agregam à estratégia das organizações. Atualmente já é possível ver alguns casos de sucesso em que o RH compõe um dos braços principais do staff de decisão nas empresas. Mas isso nem sempre foi assim, e para algumas organizações ainda não é. Por mais que o cenário atual se mostre mais promissor do que há alguns anos, o fato é que um longo caminho precisa ser percorrido para que as ações relacionadas ao desenvolvimento de pessoas sejam consideradas uma importante estratégia de negócio, capaz de alavancar significativamente as decisões de investimento. Aliar a contribuição das teorias focadas no estudo de pessoas, capital e trabalho foi um fator preponderante para o resultado deste artigo, cujo objetivo é demonstrar a importância de medir o retorno do investimento efetuado em pessoas e evidenciar como esse elemento gera valor para a organização.

Palavras-chave: ROl; capital humano; capital intelectual.

\begin{abstract}
Human resources (HR) departments have long sought to be recognized for the value they add to organizations' strategy. Currently, we can already see some success cases in which HR is one of the main arms of the decision-making staff in companies. But that was not always the case, and for some organizations it still isn't. As much as the current scenario is more promising than a few years ago, the fact is that a
\end{abstract}


long path needs to be covered so that actions related to the development of people are considered an important business strategy, capable of significantly leveraging the decisions of investment. Combining the contribution of theories focused on the study of people, capital and work was a preponderant factor for the result of this paper, whose objective is to demonstrate the importance of measuring the return on investment made in people and showing how this element generates value for the organization.

Keywords: ROl; human capital; intellectual capital.

\section{Resumen}

Las áreas de recursos humanos $(\mathrm{RRHH})$ han buscado reconocimiento durante mucho tiempo por el valor que agregan a la estrategia de las organizaciones. Actualmente, ya es posible ver algunos casos de éxito en los que RRHH es uno de los brazos principales del personal de toma de decisiones en las empresas. Pero ese no fue siempre el caso, y para algunas organizaciones todavía no lo es. Por mucho que el escenario actual sea más prometedor que era hace unos años, lo cierto es que hay que recorrer un largo camino para que las acciones relacionadas con el desarrollo de las personas se consideren una importante estrategia empresarial, capaz de apalancar significativamente las decisiones de inversión. Combinar el aporte de teorías enfocadas al estudio de las personas, el capital y el trabajo fue un factor preponderante para el resultado de este artículo, cuyo objetivo es demostrar la importancia de medir el retorno de la inversión que se realiza en las personas y mostrar cómo este elemento genera valor para la organización.

Palabras clave: ROI; capital humano; capital intelectual.

\section{Introdução}

O presente artigo tem por objetivo propor uma análise sobre a importância da mensuração do retorno do investimento efetuado em capital humano na geração de valor para a empresa e entender como a mensuração do ROI (return on investment) em capital humano pode influenciar as decisões de investimento.

Por muito tempo entendeu-se como pertinente medir apenas os investimentos em ativos tangíveis, considerando-se que a alavancagem das riquezas das organizações se dava apenas por esse caminho.

A teoria econômica do século XIX afirmava que só o investimento em ativos fixos ou imobilizados, tais como fábricas e equipamentos, poderia alavancar a riqueza da organização (FITZ-ENZ, 2001).

Sob essa ótica, naquela época cabia ao trabalhador uma remuneração tão somente por sua contribuição enquanto mão de obra. O verdadeiro valor provinha do capital investido em equipamentos. 
Em meados do século XX, o economista Theodore Schultz introduziu o conceito de capital humano, tendo como pressuposto explicar o mecanismo de geração de ganhos de produtividade e lucros de capital advindos do fator humano. No final do mesmo século, as teorias da administração finalmente vieram a aceitar que o fator humano era um diferenciador crítico na alavancagem de um empreendimento com fins lucrativos.

Nesse contexto, a associação dos dados financeiros com os dados relativos ao capital humano representa o principal caminho para o estabelecimento de indicadores que possam demonstrar aos acionistas não apenas "o que ocorreu" (dados financeiros), mas "por que aquilo ocorreu daquela forma" (dados relativos ao capital humano) (FITZ-ENZ, 2001, p. 20).

Tais premissas subsidiam o questionamento ao qual pretendemos esclarecer mediante o presente artigo: qual a importância da mensuração e da análise do retorno do investimento (ROI) do capital humano nas decisões de investimento?

Pretende-se, assim, demonstrar como os dados relativos aos investimentos em recursos humanos podem representar não só um "centro de custos", mas um valioso ativo, tornando-se fator preponderante nas decisões de investimentos de uma organização.

\section{Referencial teórico}

\section{Capital humano}

\section{A empresa tem}

seu real valor

muito além de

sua riqueza física.

Junto a ela

estão elementos

abstratos
Para melhor compreensão do conceito de capital humano enquanto ativo intangível, é necessário relembrar primeiramente o conceito de ativo. José Carlos Marion (1995, p. 53) descreve como ativos "todos os bens e direitos de propriedade da empresa, mensurável monetariamente, que representam benefícios presentes ou benefícios futuros para a empresa".

Tal conceito pode ser complementado pelo do International Accounting Standards Committee (1996, p. 64): "um ativo é reconhecido no balanço, quando é provável que a empresa venha a receber dele benefícios econômicos futuros e o ativo tem um custo ou valor que possa ser medido em bases confiáveis."

Porém, a empresa tem seu real valor muito além de sua riqueza física. Junto a ela estão elementos abstratos - ativos intangíveis. Assim, os agentes, ao movimentarem tal riqueza, geram resultados de lucratividade satisfatórios para o crescimento do patrimônio de forma eficaz e harmônica.

Segundo Flamholtz (1985 apud PACHECO, 2002, p. 41, grifos do autor), ao tratar de ativos:

[...] o critério essencial para determinar se um gasto é um ativo ou uma despesa está relacionado à noção do potencial de serviços futuros [...] os gastos com recursos humanos, quando são sacrifícios incorridos pela empresa na obtenção de serviços com 
o objetivo de obter benefícios futuros, podem ser classificados como ativos, e esses gastos devem ser tratados como despesas nos períodos em que resultam benefícios. Se tais benefícios se referem a um tempo futuro, eles devem ser tratados como ativos.

O ativo intangível passou a ter real destaque a partir da década de 1980, principalmente com a transição para a nova era do conhecimento, quando o pensamento sobre o tema deixou de se concentrar apenas na avaliação dos bens tangíveis.

Ao passo que os tangíveis são bens físicos, que possuem matéria, de modo que se pode tocá-los e enxergá-los como ferramentas que compõem estoques, veículos ou máquinas, o ativo intangível, incorpóreo ou invisível, como alguns autores o descrevem, são o contrário.

Janice e colaboradores (1995 apud PACHECO, 2002, p. 41) dizem que "pessoas não são ativos, os serviços que se espera que elas forneçam a uma organização representam os ativos". Partindo dessa definição, o capital humano também pode ser entendido como ativo humano.

Toyama e Blanco (2005), mencionando Karl Erik Sveiby (1998), defendem que perceber a importância de medir os ativos intangiveis requer quebra de paradigmas e demanda tempo. Os autores afirmam que as perdas de profissionais qualificados e de seu conhecimento (capital intelectual) não devem ser entendidas pelas empresas como uma economia de custos, mas um fator que acarretará a perda de competitividade. Partem do princípio de que as pessoas são os únicos verdadeiros agentes das empresas, por isso todos os ativos - tangíveis ou não - são frutos de ações humanas.

Sveiby (1998, p. 21) afırma que "A diferença entre o valor de mercado de uma empresa de capital aberto e o seu valor contábil líquido oficial é o valor de seus ativos intangíveis. Na maioria das empresas, o valor dos ativos intangíveis é superior ao valor de ativos tangíveis".

Ele considera, ainda, que a parte invisível do balanço patrimonial consiste em três grupos de ativos intangíveis (SVEIBY, 1998):

- Competência dos funcionários: know-how, criatividade e capacidade de agir em diversas situações para criar ativos tangíveis ou intangíveis;

- Estrutura interna: inclui patentes, conceitos, modelos e sistemas administrativos, além do hardware;

- Estrutura externa: marcas, reputação e imagem da empresa, relação com clientes e fornecedores.

Com isso, pode-se afirmar que os ativos invisíveis nas empresas variam muito. 0 conhecimento, a competência dos colaboradores, a criatividade, o relacionamento com o mercado e clientes fiéis, a marca da empresa e dos produtos, sua imagem e posição comercial, carteira de clientes, processos de produção, distribuição, gestão, inovação, informação e aprendizado podem ser citados como elementos que definem os ativos intangíveis. 
Compreendido o conceito de capital ou ativo humano, passa-se à concepção da importância da mensuração do capital humano na geração de valor para a empresa.

\section{A importância dos indicadores}

Segundo Fitz-Enz (2001, p. 4), "se não soubermos como medir nosso bem primário produtor de valor, não conseguiremos gerenciá-lo”. O mesmo autor complementa que "o advento de novas formas de contabilidade - a saber, as abordagens do valor agregado econômico e do balanced scorecard - é uma etapa promissora na direção correta" (p. 5).

Portanto, pode-se empreender que um dos desafios na mensuração do ROI do capital humano é a definição dos indicadores adequados e o estabelecimento dos meios mais eficazes para sua correta interpretação.

Campbell (1957 apud PACHECO, 2002, p. 53) defıne mensuração como "o processo de designação de números para representar qualidades". Assim, fica clara a importância de se utilizar técnicas de mensuração válidas e confiáveis, por meio de indicadores numéricos, para fornecer informações que subsidiarão as tomadas de decisões de investimentos em capital humano, chegando-se a uma pontuação que mostrará o valor do indivíduo na empresa.

\section{Um desafio na} mensuração do ROI do capital humano é a definição de indicadores adequados e meios para sua interpretação

Diversos métodos de mensuração monetária dos recursos humanos têm sido propostos por alguns autores. Entre eles, Brummet, Flamholtz e Pyle (1968), que, segundo Pacheco (2002, p. 67), sugeriram uma abordagem direta para medir o valor de um grupo. Esse método envolve "a previsão dos rendimentos futuros de uma empresa, descontá-los para determinar o valor presente da empresa e então alocar uma porção aos recursos humanos baseada em sua contribuição relativa".

Pacheco (2002, p. 68, grifos do autor), com base nessa premissa, descreve que "um método que foi proposto para mensurar o valor de uma pessoa para uma organização é denominado de modelo de recompensas estocásticas".

Os valores condicional e realizável esperados de uma pessoa por uma organização podem ser mensurados utilizando-se um modelo de valorização de recompensas estocásticas. Para tanto, segundo Vicente Pacheco (2002), deve-se:

1. Definir o conjunto de níveis e funções mutuamente excludentes que um indivíduo pode ocupar na organização;

2. Determinar o valor de cada nível para a organização;

3. Estimar o tempo de permanência esperada de uma pessoa na organização;

4. Estimar a probabilidade de que uma pessoa ocupará cada nível possível em tempos futuros especificados;

5. Descontar os fluxos de caixa futuros para determinar seu valor atual. 


\section{Capital humano e valor agregado}

De acordo com Friedman, Hatch e Walker (2000, p. 55),

as empresas estão descobrindo que as pessoas não são apenas uma despesa na demonstração do resultado, mas um ativo que não consta no balanço - um ativo que não funciona apenas acrescentando valor, mas que garante a própria sobrevivência da organização.

As organizações precisaram entender a importância de vincular os planos de capital humano à estratégia do negócio, pois sem esse vínculo a estratégia pode não ser realizada, levando o negócio ao fracasso e, consequentemente, podendo resultar em uma decisão de redução no quadro de pessoal.

Nesse ponto é importante citar uma breve definição do conceito de valor agregado. Belkaoui (1995 apud PACHECO 2002, p. 47) define que "valor agregado é o aumento na riqueza gerada pela utilização produtiva dos recursos da empresa, antes de sua destinação a acionistas, investidores, trabalhadores e ao governo".

Ultimamente, constata-se nas grandes empresas uma tendência de utilizar o valor agregado como medida de geração de riqueza. Esse processo vem substituindo o tradicional conceito de comparar receitas e despesas para identificar seu lucro.

Segundo Friedman, Hatch e Walker (2000, p. 56), "a melhoria do capital humano deve progredir em estágios - do esclarecimento à determinação de valor, ao projeto, à implementação e à monitoração".

Condição primordial é compreender que para agregar valor é necessário ter os objetivos da empresa bem definidos. A medida do capital humano só consistirá em um diferencial se for aplicada a uma situação de negócio. Assim, só se agregará valor caso os objetivos da empresa sejam colocados em primeiro plano.

\section{Mensuração do ROI do capital humano e as decisões de investimento}

\section{Contabilidade}

de RH é um

campo das

ciências contábeis

decorrente do

crescimento da

importância do

capital humano
Segundo Fitz-Enz (2001), quando se opta por uma medida em detrimento de outras para um sistema de informações de desempenho, deve-se ter em mente que os fatores selecionados são um reflexo do que se valoriza.

Ainda segundo o mesmo autor, a contabilidade tradicional deixa de solucionar as exigências dos dias de hoje em dois níveis. Primeiro, porque a contabilidade considera o interior da organização, uma vez que seu papel mais importante é o de conservar os bens da empresa comercial. Segundo, porque ela enfoca o passado. 0 autor entende que é preciso focalizar questões que criarão riquezas, ou seja, as ações que extrairão valor do mercado, e que é necessário enfocar o futuro. 
Nesse sentido, chegamos ao conceito de contabilidade de recursos humanos, que, segundo Pacheco (2002, p. 31), "desenvolveu-se de uma tradição de gerenciamento de pessoal conhecida como escola de recursos humanos, baseada na premissa de que pessoas são recursos organizacionais valiosos e, portanto, devem ser gerenciados como tal".

Contabilidade de recursos humanos é um campo das ciências contábeis decorrente do crescimento da importância do capital humano, dos conceitos e investimentos em pessoas como ativos nas empresas.

Um conceito mais amplo da contabilidade de recursos humanos, segundo a American Accounting Association (1973 apud Pacheco, 2002, p. 29), é que ela seria "o processo de identificar, medir e classificar informações sobre recursos humanos e comunicá-las aos usuários interessados".

Tal definição implica três objetivos acadêmicos principais da contabilidade de recursos humanos, humanos (PACHECO, 2002, p. 29):

1. Identificação do valor de recursos humanos;

2. Mensuração do custo e do valor das pessoas para as organi zações;

3. Investigação do impacto cognitivo e comportamental de tais informações.

Nesse sentido, é possível afirmar que a contabilidade de recursos humanos trata de um reordenamento das informações financeiras que proporciona adquirir dados sobre essa área, que podem ser utilizados por empregador e empregado com vistas à resolução de seus conflitos.

Conforme Belkaoui (1995 apud Pacheco 2002, p. 33), os objetivos funcionais da contabilidade de recursos humanos são:

- Fornecer informações sobre custo-benefício para tomada de decisões gerenciais em relação a contratação, alocação, desenvolvimento e manutenção de recursos humanos de forma a atingir objetivos organizacionais em termos de custo;

- Permitir aos gerenciadores monitorar com eficácia a utilização e desempenho dos recursos humanos da empresa;

- Possibilitar o controle de ativos, ou seja, sua manutenção, obsolescência e depreciação;

- Ajudar no desenvolvimento de ferramentas gerenciais para análise das consequências financeiras de determinadas práticas.

Segundo Pacheco (2002), a principal função da contabilidade de recursos humanos é dar suporte à gestão das empresas por meio das informações contabilizadas, visando facilitar a tomada de decisões sobre o quadro de funcionários, incluindo a contratação, o desenvolvimento e os aperfeiçoamentos, por intermédio de cursos, colocação de cargos, avaliação, recompensas e bonificações. 
Likert e Rile (1971 apud Pacheco, 2002, p. 31) ressaltam que "todos os aspectos das atividades de uma empresa são determinados pela competência, motivação e eficácia de seu quadro total de funcionários".

Verifica-se que os funcionários já são vistos e entendidos como parte do capital da empresa e por isso merecem uma atenção maior para a gestão estratégica das organizações, incluindo-os na lista de investimentos e, portanto, para os quais devem haver indicadores e mensurações.

No que se refere ao ponto de lançamento das medições na empresa, Fitz-Enz (2001, p. 28) indica que "os dados macroeconômicos são o local de lançamento de um sistema de avaliação do retorno sobre o investimento (ROI)" e que o mais comum é partir da mensuração das vendas ou da receita bruta da empresa.

Porém, para se analisar o aspecto financeiro do capital humano é necessário rever a forma tradicional da receita bruta por funcionário:

Com um mínimo de esforço, pode-se ter diversas perspectivas dos efeitos das pessoas nos resultados financeiros. Afirmar que não há qualquer meio válido e consistente de se realizar isto é simplesmente admitir nossa falta de conhecimento" (FITZ-ENZ, 2001, p. 33).

Para melhor compreensão, destacamos as definições de investimento e ROI.

Segundo Assaf Neto (2014, p. 774, 129), investimento é "a decisão de aplicação de capital com objetivo de obter um retorno que remunere o seu risco", [...] "equivale aos recursos deliberadamente levantados pela empresa e aplicados em seus negócios".

Conceitua-se ROI como "a relação entre o lucro gerado e o montante do investimento realizado" (Palmeira, 2004, p. 11).

Assim, o cálculo do ROI, de acordo com Assaf Neto (2014), é determinado pela expressão:

$$
\mathbf{R O I}=\frac{\text { Lucro gerado pelos ativos (operacional) }}{\text { Investimento médio }}
$$

Para exemplificar a relação de importância entre a mensuração do ROI do capital humano e as decisões de investimento, citamos textualmente Thomas O. Davenport (2001, p. 22):

Um trabalhador que agir como investidor de capital humano aplicará seu capital onde puder obter maior retorno. Esse retorno do investimento no trabalho [...] abrange os "lucros habituais" aos quais se referia Smith. Pensar em trabalhadores como investidores traz à tona uma realidade fundamental: investimento e retorno são uma via de mão dupla. O treinamento oferece um bom exemplo. Gerentes atentos compreendem que o aumento do conhecimento do trabalhador melhora a produtividade [...]. 
O treinamento, portanto, parece ser excelente investimento em capital humano. O crescente investimento em treinamento foi um marco na caminhada que transformou empregado-custo em empregado-ativo. Além disso, o treinamento contribui para melhorar o retorno do investimento das pessoas no trabalho. Num local de trabalho em que se aplique conhecimento intensivo, as pessoas acreditam que o aprender novas habilidades as ajudará a encontrar e manter emprego satisfatório - um emprego que pague alto retorno pelo investimento de capital humano. Além disso, a satisfação que advém da aprendizagem é, em si mesma, um retorno do capital humano que o trabalhador aplica no emprego.

Entende-se, portanto, que a combinação de indicadores confiáveis com instrumentos de medidas eficazes, como preceitua a contabilidade de recursos humanos, auxilia as empresas a melhor definirem suas decisões de investimentos futuros. Disso decorre a afirmação de que investimento e retorno são uma via de mão dupla.

\section{Conclusão}

A crescente conscientização quanto à importância dos bens intangíveis e da necessidade de avaliá-los, quantificá-los e ampliá-los resultou na certeza de que o ser humano é o principal responsável por manter uma empresa permanentemente competitiva no mercado.

As empresas

devem transpor

o conceito

simplificado de

recursos humanos

e se direcionar

ao conceito de

capital humano

Para agregar valor às pessoas, as empresas devem transpor o conceito simplificado de recursos humanos e se direcionar ao conceito de capital humano, que considera as pessoas não como recursos a serem consumidos, mas como um bem de valor a ser desenvolvido. Como exemplo, os investimentos em treinamento e a valorização profissional podem atuar, com significativa influência, no processo produtivo e mercadológico, resultando em ganhos de produtividade e qualidade.

Nesse sentido, é possível afirmar que o desenvolvimento de pessoas é um dos fatores cruciais para a sobrevivência das empresas, uma vez que delas decorre efetivamente a força do trabalho.

Fica, pois, evidenciado que o mais valioso dos capitais é aquele investido nos seres humanos e que, em uma organização, seus empregados são, definitivamente, o principal ativo.

Porém, a importância disso não se resume a investir, mas principalmente monitorar o retorno sobre esse investimento como forma de manter sua competitividade de mercado.

A prática contábil tradicional trata os investimentos em recursos humanos como despesa, e não como ativo, discriminando-o desse modo em seus papéis como "centro de custos". 
Esses demonstrativos desconsideram o fato de que a força de trabalho como um todo está associada à empresa, que representa potencial de serviços futuros e, consequentemente, rendimentos futuros, portanto deveria ser caracterizada como ativo.

A literatura pesquisada faz constatar que, apesar de ainda encontrarmos conceitos e práticas ligados à contabilidade tradicional, o que se vê é um crescimento constante voltado para a mudança desse conceito, resultando na descoberta de que os investimentos em capital humano implicam maior retorno aos acionistas.

Essa descoberta, entretanto, traz um dilema para as empresas, pois se os investimentos em capital humano resultam em retorno, resta a dúvida: como devem ser realizados e como os retornos podem ser medidos?

Portanto, é importante a compreensão do conceito de contabilidade de recursos humanos e sua utilização no gerenciamento de RH, uma vez que ela representa uma ferramenta de gestão inovadora, que permite contar com um sistema estruturado para transformar entradas (recursos humanos) em saídas (serviços humanos).

Diante desse novo entendimento, mostra-se imprescindível a mensuração do valor econômico do empregado, uma vez que os gestores precisam compreender o grau de importância de suas decisões sobre o capital humano e o retorno que esse investimento trará para as empresas.

Dessa forma, a inter-relação entre a importância da mensuração do ROI do capital humano, influenciando as decisões de investimento, podem ser confirmadas pelo presente artigo, deixando claro que os resultados dos investimentos em capital humano, se medidos e demonstrados adequadamente, podem influir significativa e positivamente nas decisões de investimentos futuros.

\section{Referências}

ASSAF NETO, Alexandre. Finanças corporativas e valor. 7.ed. São Paulo: Atlas, 2014.

DAVENPORT, Thomas O. Capital humano: o que é e por que as pessoas investem nele? São Paulo: Nobel, 2001.

FITZ-ENZ, Jac. Retorno do investimento em capital humano. São Paulo: Makroon Books, 2001.

FRIEDMAN, Brian; HATCH, James; WALKER, David M. Capital humano: como atrair, gerenciar e manter funcionários eficientes. São Paulo: Editora Futura, 2000. 
INTERNATIONAL ACCOUNTING STANDARDS COMMITTEE. Framework for the preparation and presentation of financial statements. In: INTERNATIONAL ACCOUNTING STANDARDS, 1996, London. Annals [...] London, IASC, 1996. p. 35-71.

MARION, José Carlos. Contabilidade empresarial. 5. ed. São Paulo, Atlas, 1995.

PACHECO, Vicente. A contabilidade de recursos humanos e o capital intelectual das organizações. Curitiba, Biblioteca do CRC/PR, 2002.

PALMEIRA, C. G. ROI de treinamento: dicas de como mensurar o resultado financeiro das suas ações de treinamento. Rio de Janeiro, Qualitymark, 2004.

SVEIBY, Karl Erik. A nova riqueza das organizações. Tradução de Luis Euclydes Trindade Frazão Filho. Rio de Janeiro, Campus, 1998.

TOYAMA, L.; BLANCO, M. O valor do que não se vê. Revista Canal RH, São Paulo, n. 49 , nov. 2005. 